\title{
A HAEMANGIOMA OF THE MENINGES INVOLVING THE VISUAL CORTEX
}

BY

\section{R. Foster MOORe \\ LONDON}

Johs B., aged 12 years, was sent to me on September 12, 1928, by Dr. H. W. Beach, of Hassocks, on account of defective vision of his left eye. The parents' particular concern was as to the likelihood of the right eye becoming affected, and whether he should go to school in the ordinary way. He had seen Dr. E. V. Oulton, of Hove, in 1925, when his visual acuity, with a small hypermetropic and astigmatic correction was $6 / 9$ in the right eye, and 6/12 in the left. It was stated that the left eye had got worse during the last year. 'The boy's father is said to be blind from locomotor ataxia.

He was a healthy-looking boy, and complained of nothing except defective sight of his left eye. He had a naevus of the left half of the face involving the eyelids. The left pupil reacted very poorly to light; the visual acuity of the right eye with correction was $6 / 9$ partly, and that of the left $6 / 6$ partly. There was a slight congenital dislocation of the lenses, and a small coloboma of the left optic disc. Otherwise there was no discoverable disease in the eyes themselves.

The fields of vision showed that not only the left eye, but the right eye also was affected; he had, in fact, as will be seen by the charts, an incomplete right homonymous hemianopia (Figs. 1 and 2). No previous charts were available, and so it was not possible to say whether the defect had in fact progressed within the last year, as was stated.

With regard to the cause of the lesion; in the absence of evidence of any of the common or likely causes of such a lesion such as cerebral tumour or abscess or vascular disease, and having regard to the naevus of his face and the congenital defects in both eyes, I said, in writing to Dr. Beach the same night, that I thought the likeliest cause was a naevus of the visual cortex, and suggested that a skiagram of the skull should be taken to see whether this would provide us with any fresh evidence. This was done by Dr. Prowse, and, as will be seen, the evidence is most striking. There is a tumour composed of a new growth of large vessels, evidently a haemangioma of the meninges. This tumour, when seen in a lateral skiagram, is acutely wedge-shaped (Plate I), the apex being far forward in the temporal region and apparently being situated quite superficially under the bone in this region, as is seen in antero-posterior skiagrams. (Plate II.) The base of the wedge 
Plate 1. 


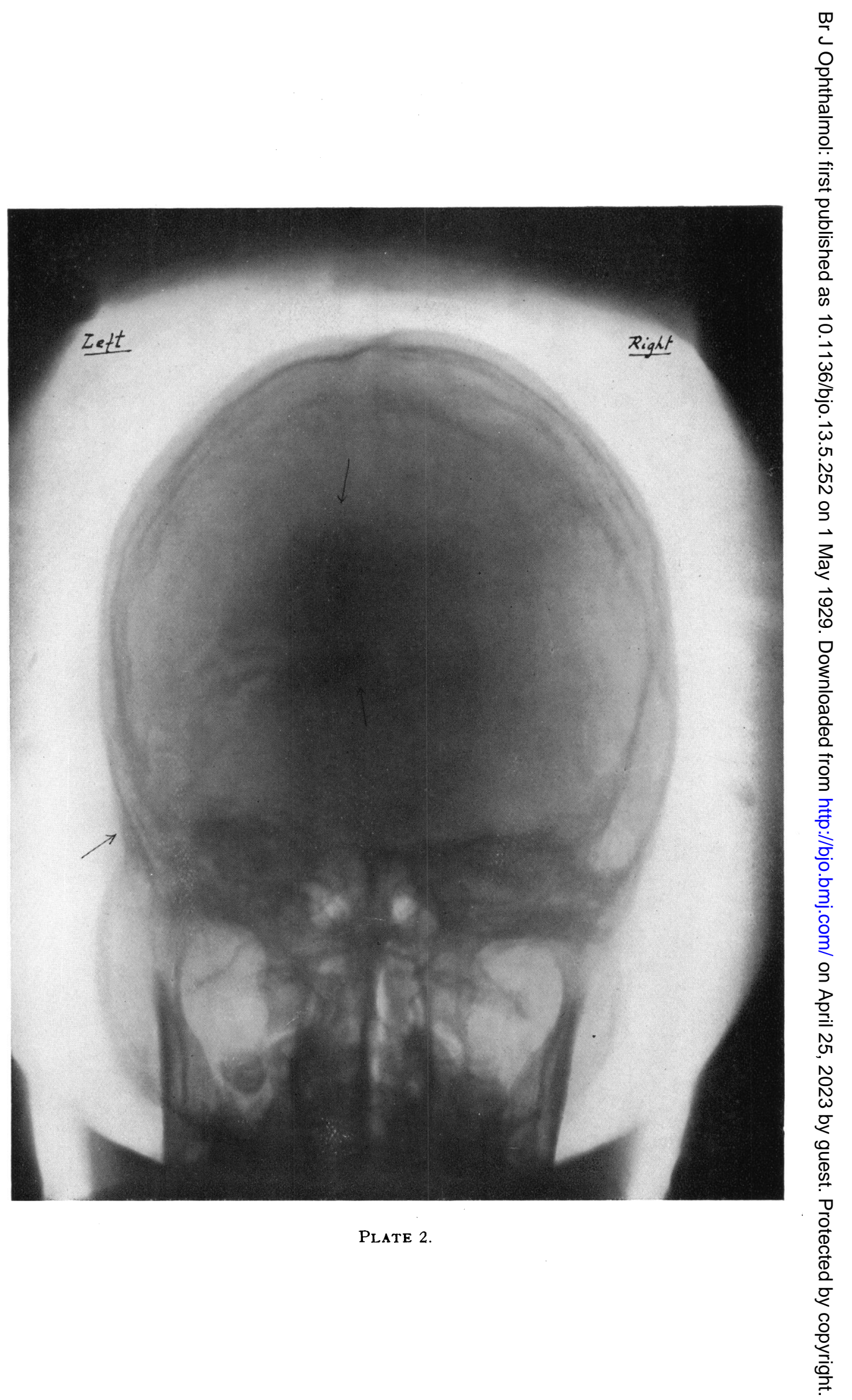




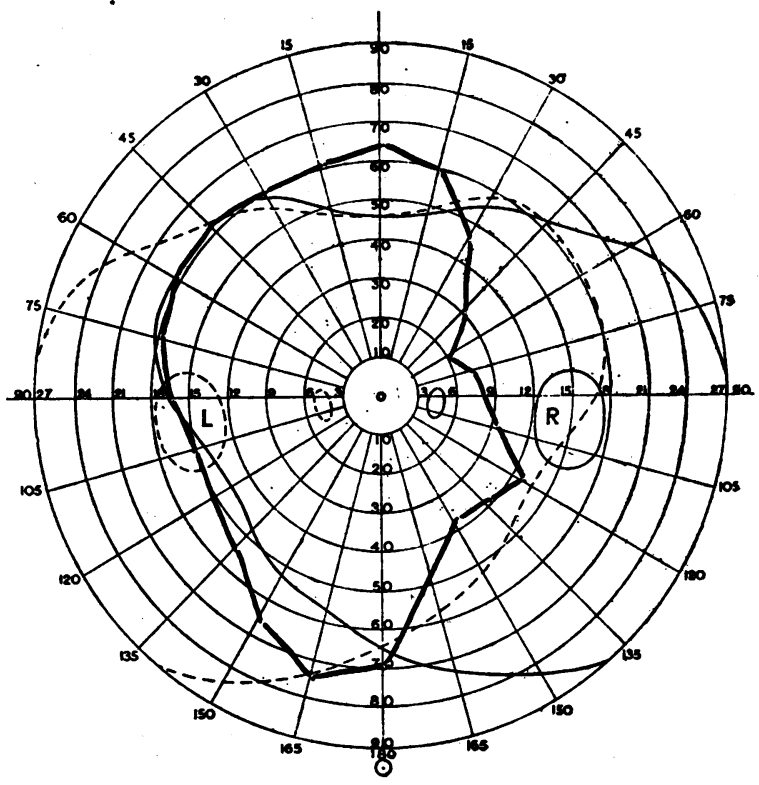

FIg. 1.

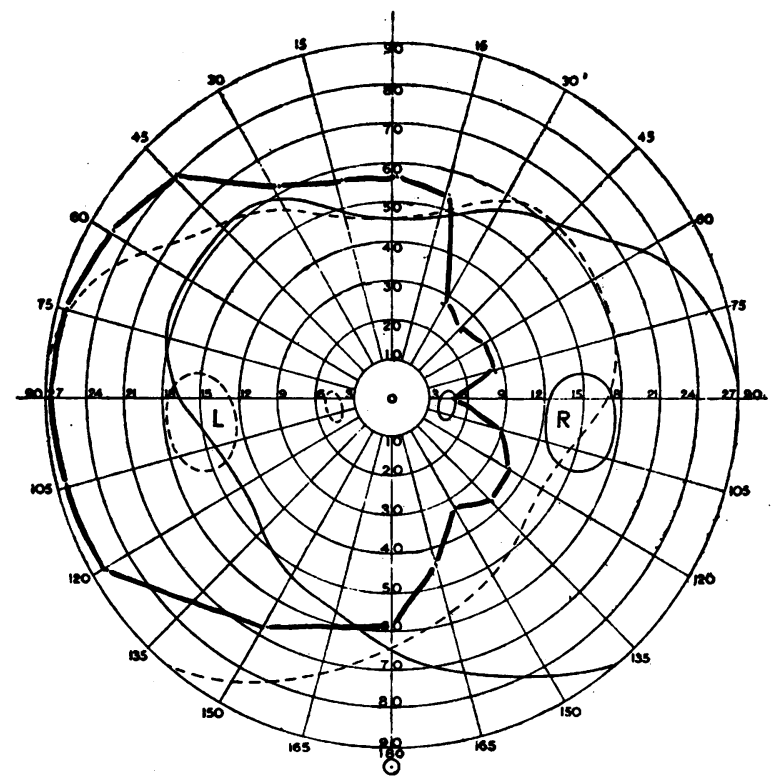

FIG. 2. 
is at the occipital pole, immediately above the tentorium and is therefore closely related to the visual cortex. I am told by radiologists that the vessel walls must have undergone calcification in order to produce so dense a shadow.

With regard to the particular enquiries for which he was brought to me, I pointed out first that the right eye was already involved, and secondly I said I saw no reason why he should not go to school in the ordinary way but that he should be entirely debarred from vigorous exertion, such as football, etc.

At a later date, after the $\mathrm{X}$-rays had been taken and the diagnosis had thus been completed, he was seen by Dr. C. P. Symonds, who has made reference to him in the discussion following Dr. Parkes Weber's paper on Cerebral Haemangiomata, in the Proc. of the Roy. Soc. Med., 1929, Vol. XXII, 4, page 431.

A number of cases of this kind have been reported by various observers. Apparently the first in which evidence of a calcified meningeal haemangioma was recognised by X-ray examination on the living patient was that of Parkes Weber, in 1922. (Jour. of Neur. and Psychopath., 1922, Vol. III, 134.) Previous to this they had been discovered at autopsy ; thus D'Arcy Power reports a case (Trans. Path. Soc., 1888, XXXIX, 4.) in which the mass of vessels extended deeply into the brain substance, and Drysdale (Ibid. 1904, IV, 60) reported two cases, also with autopsies, in which a similar condition was present. Since that time a number of cases of such tumours involving different parts of the brain and indeed the spinal cord have been discovered, and have often been associated with naevi of the skin of the face, having a trigeminal distribution, or in the case of the spinal cord, a distribution along the corresponding spinal nerve. These naevi, when present, often serve to point the diagnosis, as in the present case, but the intracranial naevi do not always have any such external indication as to their nature.

These meningeal haemangiomata are of very special interest to $o_{i}$ hth thalmic surgeons from several points of view. In the first place is their association with congenital malformations of the eyes themselves. Of these the most striking is the frequent presence of buphthalmos. It was present in three of Cushing's cases (Harvey Cushing, Jl. Amer. Med. Assoc., 1906, XLVII, 178), two cases of Brushfield and Wyatt (Brit. Jl. of Child. Dis., 1914, XI, 25), and two cases of 'T. R. Aynsley (Brit. Jl. of Child. Dis., 1928, XXV, 197), and one case of Parkes Weber (Loc. cit., 1922). In Parkes Weber's case the buphthalmic eye became blind and ulcerated, and was afterwards removed by Dr. C. Markus, and it is of interest to observe that Dr. Markus found no evidence of an intraocular naevus. 
Another ocular abnormality is heterochromia iridis. This has been referred to by Parkes Weber who states that it was present in his own case, in one of Brushfield and Wyatt's, and in Sheldon's case. I have no note of it in my present case, but I have had the opportunity of examining a case of Mr. L. B. Rawling's which at present is not reported, and in which the iris on the side of the haemangioma was more heavily pigmented than on the opposite side. The difference in the colour of the iris, unless it is well marked, is readily overlooked, and this is particularly likely to happen if the irides are dark in colour, or perhaps the difference is observed but is looked upon as of no interest. In the case to which I have just referred the heterochromia might readily have escaped detection except for the fact that one suspected it might be present, and I think it likely that were all cases examined especially carefully with regard to this point it would prove to be common.

In other cases other mild malformations occur which perhaps do not easily obtrude themselves. In the present case it had been suggested that there was partial optic atrophy in the left eye and that this fitted in with the defective sight of which the boy complained. The apparent pallor of the disc, however, was due to the presence of a small congenital coloboma, which was not present in the right eye. There was a slight degree of congenital displacement of the lenses of both eyes.

In Mr. Rawling's case referred to above, the eye on the side of the lesion had a high degree of mixed astigmatism, whereas the opposite one was normal.

Lastly there is the important question of the involvement of the optic radiations and the visual cortex by the tumours giving rise to homonymous defects in the fields of vision. This is well exemplified in the present case. In one of Mr. Rawling's cases, which I have examined, and to which I have referred above, in which he found at operation a large naevus over the parietal region of the right side of the brain, there was, as one would expect, no defect in the visual fields, but in his other case, which I have not at present had an opportunity of seeing, it would seem exceedingly likely from the appearance of the skiagrams, and from the great similarity to my own case that a defect of the field of vision would be found.

It will be noticed as a striking fact in all the above instances, that the abnormality of the eye, whether it is buphthalmos, heterochromia iridis, coloboma of the disc, or a high refractive error, was on the same side as the tumour of the brain, the only exception being the dislocation of the lens which was present in both eyes.

Having regard to the frequency with which buphthalmos has been found to be associated with intracranial haemangioma, it would seem worth while to have a skiagram taken of the skull in 
any case of buphthalmos, on the chance of intracranial haemangioma being present. I have had one case of double buphthalmos examined in this way since commencing this paper and in it no tumour was shown by X-ray.* I suggest too that a more critical examination of the eyes in these cases is likely to reveal a greater incidence of the defects referred to above than has been found in the past.

The association of retinal haemangiomatosis, Coats' disease ( $v$. Hippel's disease), with haemangioma of the cerebellum and sometimes other parts of the body has been pointed out by Lindau, and Parkes Weber makes the suggestion that the scattered cases of Coats' disease which have been reported in this country should be re-examined with regard to the possible occurrence of a cerebellar haemangioma.

I published in 1914 (Roy. Lon. Ophthal. Hosp. Reports, 1914, XIX, Part III, 411) the first case of a melanoma of the choroid which had been examined ophthalmoscopically during life and was afterwards obtained for pathological investigation owing to the death of the patient from myasthenia gravis, and in the first volume of this Journal I published a second case in which I obtained the specimen for pathological examination owing to the death of the patient from a cerebral tumour. de Schweinitz and Shumway (Trans. Amer. Ophthal. Soc. 1905, X, 439) published what seemed to be a similar case, which was discovered post mortem in a patient who also had died of a cerebral tumour.

Melanomata of the choroid are not very common, but are not exceedingly rare. They do not undergo change. I have recently ascertained that the patient from whom the coloured drawing in the Moorfields Reports referred to above was made, is quite unchanged after fifteen years. At the same time, having regard to the above mentioned cases, and to the group with which we are now dealing, I repeat the suggestion that I made when showing the above case at a meeting of the Ophthalmological Society some ten years ago that the possible association of choroidal melanomata with intracranial tumours should be watched for.

\footnotetext{
* I have since had another case of my own examined and Miss Ida Mann has been good enough to allow me to have a case of her own examined, and in both cases the result was negative.
} 